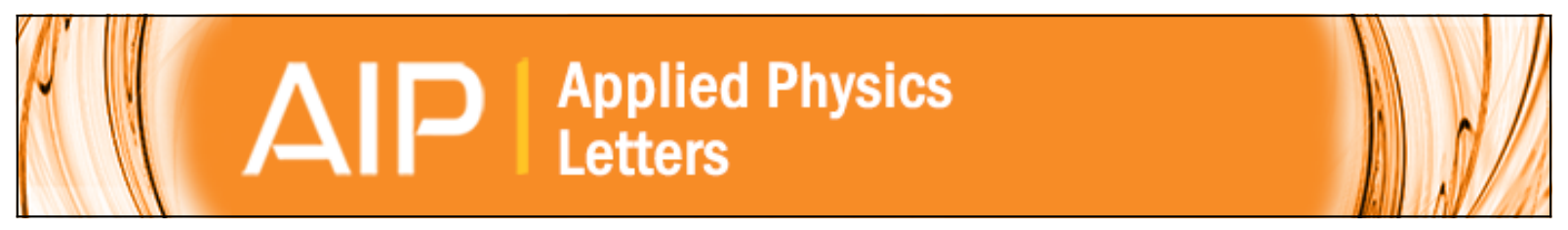

\title{
Origin of scintillation in ceriumdoped oxide crystals
}

M. V. Korzhik and W. P. Trower

Citation: Applied Physics Letters 66, 2327 (1995); doi: 10.1063/1.113971

View online: http://dx.doi.org/10.1063/1.113971

View Table of Contents: http://scitation.aip.org/content/aip/journal/apl/66/18?ver=pdfcov

Published by the AIP Publishing

\section{Over 700 papers \&}

presentations on

multiphysics simulation visw now

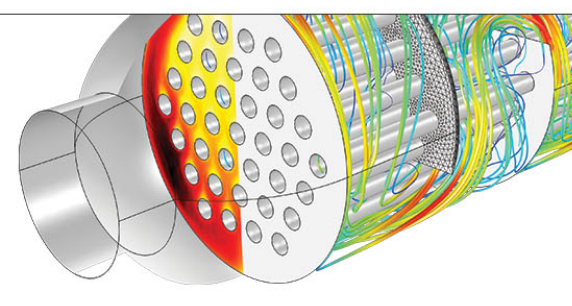




\title{
Origin of scintillation in cerium-doped oxide crystals
}

\author{
M. V. Korzhik ${ }^{\text {a) }}$ and W. P. Trower ${ }^{\text {b) }}$ \\ Physics Department, Virginia Tech, Blacksburg, Virginia 24061
}

(Received 10 November 1994; accepted for publication 7 March 1995)

\begin{abstract}
We propose here a model of the scintillation from complex oxide single crystals doped with $\mathrm{Ce}^{3+}$ ions to explain the correlation observed between scintillation light yield and intrinsic luminescence of the matrix. (C) 1995 American Institute of Physics.
\end{abstract}

Single oxide crystals doped with cerium ions have now joined alkali halides as scintillators of choice for particle and radiation detection applications. Such new phosphors were found in experimental searches unaided by theory, and include: $\mathrm{Y}_{3} \mathrm{Al}_{5} \mathrm{O}_{12}$ (YAG), $\mathrm{Y}_{2} \mathrm{SiO}_{5}$ (YSO), $\mathrm{YAlO}_{3}$ (YAP); $\mathrm{GdAlO}_{3}$ (GAP), $\mathrm{Gd}_{2} \mathrm{SiO}_{5}$ (GSO); $\mathrm{Lu}_{3} \mathrm{Al}_{5} \mathrm{O}_{12} \quad$ (LuAG), $\mathrm{Lu}_{2} \mathrm{SiO}_{5}$ (LuSO), and $\mathrm{LuAlO}_{3}$ (LuAP). Although the unguided random sampling of solid-solution compounds has identified some promising new scintillator candidates, ${ }^{1}$ once identified, growing a crystal of the material is an expensive process with an uncertain outcome. If common properties of good scintillators could be identified then materials which in their crystalline form might possess these characteristics could be preferentially pursued.

A scintillator's efficiency is well described by $\left[\left(h \nu_{e}\right) /\left(\beta E_{g}\right)\right] S Q$, where $h \nu_{e}$ is the average emitted photon energy, $\beta E_{g}$ is the average crystal electron-hole pair creation energy, $S$ is the host matrix electron-hole to luminescent center energy transfer efficiency, and $Q$ is the luminescent center quantum efficiency. ${ }^{2} Q$ is easily determined directly and methods to estimate $\beta E_{g}$ have been developed. ${ }^{3}$ However, the matrix to radiating ion energy transfer and its influence on the scintillator parameters is still debated. Despite an attempt to describe its obvious limits ${ }^{4}$ and the proposing of some common rules, ${ }^{5}$ only for simple gadolinium-based crystals (in which the initial and final excited states are determined) has the scintillation mechanism been described. ${ }^{6}$

The lack of experimental information about the host matrix excited states has until now prevented the construction of an adequate model of the energy transfer from the matrix to the radiating centers in cerium-doped oxide single crystals. Such information can only be obtained from spectroscopic data, including intrinsic luminescence, of undoped crystals. However, such data are susceptible to corruption by impurities. In what follows we show that the scintillation efficiency of cerium-doped single oxide crystals strongly depends on the presence and parameters of the intrinsic luminescence of the host matrix.

We excited undoped YAG, LuAG, YAP, and YSO single crystals of dimensions $10 \times 10 \times 1 \mathrm{~mm}^{3}$ at room temperature with $122 \mathrm{keV} \gamma$ rays from cobalt-57 and measured the luminescence spectra with the setup described elsewhere. ${ }^{7}$ The crystals, from a collection of those grown in the Soviet

\footnotetext{
a) Permanent address: Institute for Nuclear Problems, Belarus State University, Minsk, Belarus.

${ }^{b)}$ Electronic mail: trower@vtcc1.cc.vt.edu
}

Union over two decades, were selected for their minimal ultraviolet absorptivity. The intrinsic luminescent band parameters, together with those previously reported, are listed in Table I. The short wavelength bands for LuAG and YSO could not be detected due to absorption effects that our selection efforts failed to overcome.

We identified a long wavelength luminescence band in all crystals, at shorter wavelength by $\sim 2000 \mathrm{~cm}^{-1}$ in the yttrium materials than in our lutetium sample. The shape and proximity of these bands in all our crystals suggest a common origin. A detailed investigation of YAG and YAP associated this emission with electron-hole recombination near cation vacancies. ${ }^{8}$ Further, the excitation spectra of this luminescence has been determined to be near the long wavelength edge of the fundamental excitation. ${ }^{9-11}$ Our luminescence data and those of others ${ }^{12}$ are consistent in indicating a common origin of these luminescence bands in the radiative recombination $(\mathrm{Sh}+e)$ relaxation of excitons from selftrapped holes $\mathrm{Sh}$ near the $\mathrm{Y}^{3+}$-ion vacancies. These hole centers located inside complex crystals like YAG and are temperature stable. $^{13}$

The short wavelength bands have been previously investigated only in YAG and YAP. Using optical detected magnetic resonance, YAP was shown to have emitting state wave functions which extend to at least a unit crystal cell. ${ }^{14}$ Since this band was not seen in thermally stimulated luminescence spectra $^{9}$ it cannot result from the radiative recombination of separated charge centers. Thus, these bands are probably produced by the annihilation $(\mathrm{Sh}+\mathrm{Se})$ of self-trapped excitons with weak Coulomb binding whose radius is on the order of one unit cell.

Therefore the initial excited states of complex oxide crystals, gadolinium-based crystals excepted, are self-trapped $(\mathrm{Sh}+\mathrm{Se})$ excitons with weak Coulomb binding and excitons of self-trapped $(\mathrm{Sh}+e)$ holes near the heaviest host ion va-

TABLE I. Intrinsic luminescence by $122 \mathrm{keV} \gamma$-ray excitation.

\begin{tabular}{|c|c|c|c|}
\hline & $\begin{array}{c}\text { Short } \nu \\
\text { band }\end{array}$ & $\begin{array}{c}\text { Long } \nu \\
\text { band }\end{array}$ & $\begin{array}{c}\text { Other } \\
\text { references }\end{array}$ \\
\hline $\begin{array}{c}\mathrm{Y}_{3} \mathrm{Al}_{5} \mathrm{O}_{12} \\
(\mathrm{YAG})\end{array}$ & $39200 \mathrm{~cm}^{-1}$ & $33600 \mathrm{~cm}^{-1}$ & $8,9,11$ \\
\hline $\begin{array}{c}\mathrm{Lu}_{3} \mathrm{Al}_{5} \mathrm{O}_{12} \\
(\mathrm{LuAG})\end{array}$ & $\ldots$ & $31250 \mathrm{~cm}^{-1}$ & 15 \\
\hline $\begin{array}{l}\mathrm{YAlO}_{3} \\
\text { (YAP) }\end{array}$ & $44800 \mathrm{~cm}^{-1}$ & $33600 \mathrm{~cm}^{-1}$ & $9-11,14$ \\
\hline $\begin{array}{l}\mathrm{Y}_{2} \mathrm{SiO}_{5} \\
(\mathrm{YSO})\end{array}$ & $\cdots$ & $33200 \mathrm{~cm}^{-1}$ & $\cdots$ \\
\hline
\end{tabular}




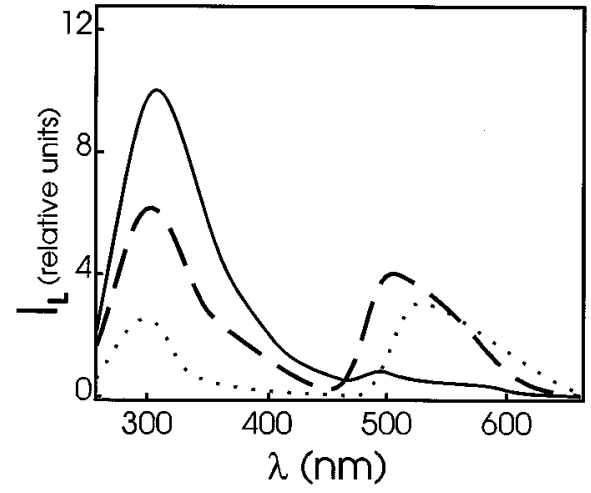

FIG. 1. Luminescence intensity in relative units with wavelength resulting from the $122 \mathrm{keV} \gamma$-ray excitation of cerium-doped garnets at $\sim 300 \mathrm{~K}$. Solid line is $\mathrm{Lu}_{3} \mathrm{Al}_{5} \mathrm{O}_{12}$ : Ce $\left(0.001\right.$ mass \%); broken line is $\mathrm{Lu}_{3} \mathrm{Al}_{5} \mathrm{O}_{12}$ : $\mathrm{Ce}$ $\left(0.1\right.$ mass \%); and dotted line is $\mathrm{Y}_{3} \mathrm{Al}_{5} \mathrm{O}_{12}$ : $\mathrm{Ce}(0.2$ mass \%).

cancies. For cerium-doped crystals there are at least two possible energy transfers between the host matrix and radiating ion which can produce luminescence. Each energy transfer efficiency depends strongly on the exciton luminescence and $\mathrm{Ce}^{3+}$ absorption band resonances, Calculations of the $\mathrm{Ce}^{3+}$-ion energy level structure ${ }^{15}$ show good energy coincidence for YAG and YAP between the upper $\mathrm{Ce}^{3+} 5 d^{1}$ configuration Stark components and the $(\mathrm{Sh}+\mathrm{Se})$ luminescence bands. The lowest $5 d^{1} \mathrm{Ce}^{3+}$ Stark components have good coincidence with $(\mathrm{Sh}+e)$ luminescence only for YAP, becoming progressively worse for YSO and YAG. This agrees with the measured light yields: 14000,10000 , and 9000 photons per $\mathrm{MeV}$, respectively. ${ }^{16,17}$

Although $(\mathrm{Sh}+e)$ luminescence is partially quenched in cerium-doped garnets, it is even present in crystals with considerable cerium ion concentrations, as seen in Fig. 1. On the other hand, for YAP the intensity of both intrinsic bands is decreased by more than an order of magnitude when the cerium content is only $\sim 100 \mathrm{ppm}$.

The large LuSO light yield ${ }^{15}$ is consistent with our scintillation model. The $(\mathrm{Sh}+e)$ luminescence maximum shifts to a larger wavelength in LuAG relative to YAG. This same process operating in LuSO and is stronger than in YSO since there are better resonance conditions between the lowest $5 d^{1}$ configuration Stark components and $(\mathrm{Sh}+e)$ luminescence. Because of the ion radius difference between $\mathrm{Lu}^{3+}$ $(0.85 \mathrm{~A})$ and $\mathrm{Ce}^{3+}(1.03 \mathrm{~A})$, cerium incorporation in LuSO will be accompanied by a high cation vacancy density which compensates for size. Therefore the $(\mathrm{Sh}+e)$ state density should be comparably higher in LuSO than in yttrium-based crystals. Thus, we predict that the light yield of LuAP will, after the growth and treatment technology is perfected, be higher than for YAP.

Our proposed scintillation mechanism also explains the limited light yield of cerium-doped gadolinium-based crys- tals. Here, although $(\mathrm{Sh}+\mathrm{Se})$ as well as $(\mathrm{Sh}+e)$ states are quenched by host matrix $\mathrm{Gd}^{3+}$ ions, which are only intermediaries between excitons and $\mathrm{Ce}^{3+}$ ions. The $\mathrm{Gd}^{3+}$-ion luminescence is strongly quenched by migration processes which limit the total light yield.

Our model explains the scintillation kinetics and the slow components at the kinetics extrema. For instance, the YAP $(\mathrm{Sh}+e)$ luminescence kinetics has large time components $^{10}$ with lifetimes $\sim \mu$ s. In the Forester-Dexter model these components arise in the acceptor (i.e., $\mathrm{Ce}^{3+}$ ) kinetics and have been observed. ${ }^{7,16,17}$

We have described a model of scintillation from ceriumdoped complex oxide crystals which explains the main features of our experimental data and that of others. We hope that our model can inform future efforts which will result in a theory of these crystals of increasing practical importance.

The authors thank our many colleagues who have generously provided our undoped crystals without which our investigations and model would not have been possible. This work was performed under a grant from the National Science Foundation.

${ }^{1}$ S. E. Derenzo, W. W. Moses, J. L. Calhoun, and R. C. C. Perera, IEEE Trans. Nucl. Sci. NS-37, 203 (1990).

${ }^{2}$ G. Blasse, J. Lumin. 60\&61, 991 (1994).

${ }^{3}$ D. J. Robbins, J. Electrochem. Soc. 127, 2694 (1980).

${ }^{4}$ A. Lempicki and A. J. Wojtowicz, J. Luminescence 60\&61, 942 (1994); A. Lempicki, A. J. Wojtowicz, and E. Berman, Nucl. Instrum. Methods A 333, 304 (1993).

${ }^{5}$ D. J. Robbins, B. Cocklane, J. L. Grospher, and B. Lent, J. Electrochem. Soc. 126, 1221 (1979).

${ }^{6}$ V. G. Baryshevsky, D. M. Kondratiev, M. V. Korzhik, V. B. Povlenko, and A. A. Fyodorov, J. Luminescence 60\&61, 956 (1994); H. Suziki, T. A. Tombrello, C. L. Melcher, C. A. Peterson, and J. S. Schweitzer, Nucl. Instrum. Methods A 346, 510 (1994).

${ }^{7}$ V. G. Baryshevsky, M. V. Korzhik, B. I. Minkov, S. A. Smirnova, A. A. Fyodorov, P. Dorenbos, and C. W. E. van Ejik, J. Phys. Condens. Matter 5, 7883 (1993)

${ }^{8}$ W. Hayes, M. Yamaga, D. J. Robbins, and B. Cocklane, Solid State Phys. 13, L1085 (1980).

${ }^{9}$ A. I. Kuznetsov, B. R. Namosov, and V. V. Murk, Phys. Solid State (USSR) 27, 3030 (1985).

${ }^{10}$ A. I. Kuznetsov, V. N. Abramov, B. R. Namosov, and B. R. Uibo, Proc. Phys. Inst. Estonian Acd. Sci. 53, 83 (1982) (in Russian).

${ }^{11}$ A. I. Kuznetsov, V. N. Abramov, V. V. Murk, and B. R. Namosov, Sov. Phys. Solid State 33, 2000 (1991).

${ }^{12}$ N. Yu. Konstantinov, L. G. Karaseva, and V. V. Gromov, Dokl. Akad. Nauk SSSR 255, 631 (1980) (in Russian).

${ }^{13}$ N. J. Konstantinov, E. A. Karaseva, and A. N. Ermolkin, Sov. J. Phos. USSR Acad. 250, 631 (1980) (in Russian).

${ }^{14}$ R. L. Wood and W. Hayes, Radiat. Eff. 72, 195 (1983).

${ }^{15} \mathrm{~J}$. Andriessen, P. Dorenbos, and C. W. E. van Eijk, in Scintillators and Phosphor Materials, edited by M. J. Weber, P. Lecoq, R. C. Ruchti, C. Woody, W. M. Yen, and R.-y. Zhu (Material Research Society, Pittsburgh, PA 1994), p. 355.

${ }^{16}$ P. Dorenbos, M. V. Korzhik, A. P. Kudravtseva, S. V. Lubetsky, B. I. Minkov, V. B. Pavlenko, and A. A. Fyodorov, J. Appl. Spectros. (USSR) 59, 226 (1993).

${ }^{17}$ P. Dorenbos and J. T. M. de Haas, Stratech Report No. 94-03, TU Delft, Netherlands (unpublished). 